\title{
The Correlative Study of Health Literacy and Health Status for Diabetic Patients in Taiwan
}

\section{Chia-Lun Lo}

Department of Health Business Administration, School of Nursing, Fooyin University, 151 Jinxue Rd., Daliao Dist., Kaohsiung City 83102, Taiwan

\author{
Article Details \\ Article Type: Research Article \\ Received date: $13^{\text {th }}$ August, 2018 \\ Accepted date: $3^{\text {rd }}$ November, 2018 \\ Published date: $23^{\text {rd }}$ November, 2018
}

"Corresponding Author: Chia-Lun Lo, Department of Health Business Administration, School of Nursing, Fooyin University 151 Jinxue Rd., Daliao Dist., Kaohsiung City 83102, Taiwan. E-mail: allenlo.tw@gmail.com

Citation: Lo CL (2018) The Correlative Study of Health Literacy and Health Status for Diabetic Patients in Taiwan. J Pub Health Issue Pract 2: 125. doi: https://doi.org/10.33790/jphip1100125.

Copyright: $\mathbb{C} 2018$, This is an open-access article distributed under the terms of the Creative Commons Attribution License 4.0, which permits unrestricted use, distribution, and reproduction in any medium, provided the original author and source are credited.

\section{Abstract}

The healthcare market has many characteristics that distinguish it from other industries, among which asymmetric information is the most frequently discussed. Oftentimes, due to limited access to information, patients are unable to gain full health information and make the most appropriate choices or decisions, regardless of whether or not they are under physician supervision or engage in self-care at home. Hence, the enhancement of health information and health literacy is the crucial option for improving the health status of the general public. The purpose of this paper is to explore the relationship model to determine the impact of health literacy on health status of people with diabetes.

Diabetic patients keep good health literacy and self-care skills might be important factor to diabetes stability. Therefore, we used the self-developed "Specific Disease (Diabetes) Chinese-Test of Health Literacy Assessment; C-TOHLA" and 12-item short form health status assessment (SF-12) as the research tools to evaluate the diabetic patients self-care skill from outpatient clinics of seven hospital in Taiwan.

The results showed that the level of health literacy directly affects the overall mental health status, but through the mediating variables of doctor's order compliance, the overall physiological health produce significant differences. In addition, in terms of the health literacy dimension defined in this study, the general public's arithmetic capability remains the weaker part. In conclusion, the level of daily care ability directly produces the greatest impact on the overall health status of the general public. Hence, in order to enhance the health status of people, the ability that must be enhanced is the self-care ability.

Keywords: Health literacy, Health information, Self-care, Diabetes

\section{Introduction}

The healthcare markethas many characteristics that distinguish it from other industries, among them asymmetric information is considered an important issue. Because of the limited medical knowledge of medical users (patients), when communicating with medical personnel, it may be impossible for patients to gain comprehensive understanding of what they hear, thus resulting in misunderstanding between both sides. Patients themselves are unable to effectively promote their own health due to their relatively limited health knowledge. This ability that has been studied in foreign countries J Pub Health Issue Pract

Volume 2. 2018. 125 for years is known as "health literacy" (translated as health literacy in this research).

According to the National Assessment of Adult Literacy, NAAL conducted in 1993, the results show that about 90 million Americans (accounting for $47 \%$ of the total population) have trouble adapting to the current healthcare system, thus the lack of health literacy skills and the failure to obtain appropriate healthcare information needed to determine and obtain healthcare services [1]. Even though nearly a decade has passed, a survey conducted by NAAL still shows that not much progress has been made as far as the American people's health literacy is concerned. The Institute of Medicine (IOM) in the United States obtained similar findings after viewing over 300 articles. Most of the people cannot understand the healthcare information they obtain, while the majority of the healthcare information providers (medical personnel) overestimate patients' ability to understand (the level of health literacy). Therefore, unless patients' health literacy can be simultaneously enhanced, it will be impossible for them to achieve goals such as improving healthcare quality, reducing medical costs, or reducing medical asymmetry, self-care and social asymmetry. On the other hand, according to the health literacy related survey literatures of American Medical Association, it was also pointed out that people with relatively poorer health literacy tend to produce more healthcare wastes [2]. Hence, the level of health literacy has a certain impact on patients' safety and health results. If patients' health literacy ability can be enhanced, patients' safety and health status can also be effectively improved, thereby resulting in effective health care utilization. Hence, the enhancement of health literacy is indeed helpful for doctor-patient communication, which ultimately benefits patients' self-care ability and health status.

According to the literatures, health literacy is defined as: "The achievement of a level of basic health information and services to take action into appropriate health decisions", "By gaining an insight into this method, the adopter can understand the contents and methods of health knowledge" [3], and "Health literacy represents the cognitive and social skills which determine the motivation and ability of individuals to gain access to, understand and use information in ways which promote and maintain good health" [4]. Based on a book on health literacy published by IOM literacy is divided into basic literacy and functional literacy. The former refers to the general ability to read, write, and understand commonly used words. This ability is usually associated with basic knowledge or 
educational background; the latter refers to the literacy required to achieve special purposes. People with a higher educational background has the ability to keep their health status. These people can obtain related health knowledge to acquire the health integrity and harmony of the body by implementing goal-oriented behaviors, competent self-care, satisfactory relationships with others, and adjustment and adaptability to the external environment [5]. Nut beam further mentioned that the framework of health literacy should cover three aspects: basic function, interactive function, and critical nature. The basic functions only include reading and writing health education related basic health knowledge and health equipment use, while the interactive function represents the people's taking the initiative to understanding of different forms of health information and concepts through communication and their active participation in health activities. Finally, the critical function covers more social skills and the ability to judge the correctness of the health knowledge acquired [6]. Based on the above, health literacy is not the same as health knowledge-the ability to read a wide range of health knowledge, but without adequate comprehension and judgment, the so-called literacy can never be enhanced. In the past, health literacy related researches had mostly been conducted in English-speaking countries. Beside the difficulties involved in directly applying these researches in countries with different writing systems, as the writing system is in "alphabetic writing", the measurement tools are generally focused on the print literacy, thus making them inadequate as representatives of the level of health literacy, or proof of the relevance between health literacy level and health.

Therefore, to explore whether or not health literacy had an impact on health quality, with patients with a single disease as the study subjects, the research aims will be better achieved if interferences from other factors can be eliminated where appropriate. Hence, diabetic patients were selected in this study as the study subjects, as the self-care ability level is considered highly important to them. Through the selfdeveloped Chinese-Test of Health Literacy Assessment; C-TOHLA measurement tool for specific diseases, and in coordination with the 12-item short form health status assessment, SF-12 screening scale, the people with poorer literacy were distinguished to facilitate appropriate health education and enhance the people's health literacy level, thereby improving their health status.

\section{Literature Review}

Regarding past literacy related research findings, it was found that the people's health literacy level is indeed less than adequate. For example, according to the results of a research conducted by Williams et al. in 1995, it was pointed out that the respondents whose mother tongue was Spanish accounted for as high as $61.7 \%$ [7]. It was also found in the study that about $26 \%$ of the respondents did not understand the subsequent outpatient clinic appointment scheduled, while $60 \%$ of the people did not understand the contents on the consent form. Gazmararian et al. conducted a survey on seniors aged over 65 in four regions in the United States that had just purchased Medicare insurance policies, totaling 3,487 seniors. The results show that $34 \%$ of those whose mother tongue was English and 54\% of those whose mother tongue was Spanish had inadequate or average health literacy. It was also found in the study that age, region of residence, language system, educational level, and occupation were the relevant factors affecting the level of health literacy [8]. Most researches listed health status as the outcome variable of health literacy, but the relationship between the two did not reach consistent results. Some research results indicated a correlation [9-12], while others did not $[7,13,14]$. As some literatures suggest, "compliance behavior" is a mediating variable, which refers to whether or not one can comply with medical personnel's advice and change one's health behavior to acquire a sound health status $[7,15,16]$. From the evidence, it was found that no conclusions have been drawn regarding the influence of the level of health literacy on health status, the key lies in measuring the health literacy, good or bad and the availability of a set of appropriate health literacy test tool that leads to the precise understanding of adult health literacy related issues and the discovery of the population with poor health literacy.

In view of the health literacy measurement tools commonly used by the academic circle in the United States, there are generally three types: the Wide Range Achievement Test (WRAT) [17] developed by Wilkinson in 1993, the Rapid Estimate of Adult Literacy in Medicine (REALM) [18] developed by Davis in 1994, and Test of Functional Health Literacy in Adults (TOFHLA) [19] developed by Parker in 1995. These types of literacy measurement tools are primarily used to test the general public's degree of understanding of English medical terms. However, as the education, text system, and customs of the other countries differ, they cannot be directly applied. At the same time, these scales only target general problems that take place during medical appointments, their relevance with self-care and healthcare is negligible. After a discussion with the healthcare professionals, it is deemed that everyone has different understanding of the various diseases. If an individual has contracted a specific disease and has already sought medical attention, the health education imparted by medical personnel will generally be accepted by that individual. Under this health knowledge basis, adequate knowledge is essential for enhancing health literacy and internalize it into a compliance behavior to improve the individual's own health. If the knowledge is inadequate for improvement, it means the individual's health literacy is poor. Hence, this study deems the specific disease-health literacy scale vital for testing patients' health literacy level.

Based on the above reasons presented, patients that required adequate self-care and diabetic patients with a higher prevalence were adopted as the study subjects. Through the self-developed diabetes health literacy scale, a research survey was conducted targeting the diabetic group. Moreover, the SF12 overall health quality questionnaire commonly used overseas to test the overall health status was adopted to gain an insight into the crucial factors contributing to the enhancement of diabetic patients' health literacy. Further, the mediating effects of the doctor's order compliance behaviors were tested.

\section{Research Methods}

\section{Research Framework}

This paper aimed to explore the relationship between the patients' health literacy and health status on people with diabetes. Thus, through the development of the Chinese-Test of Health Literacy Assessment; C-TOHLA, the targeted general public's literacy level concerning relevant diseases was measured. Also, the rapid measurement tool SF12 for health quality served as the dependent variable for measuring the overall health status and disease control. The overall research framework is as shown in Fig. 1:

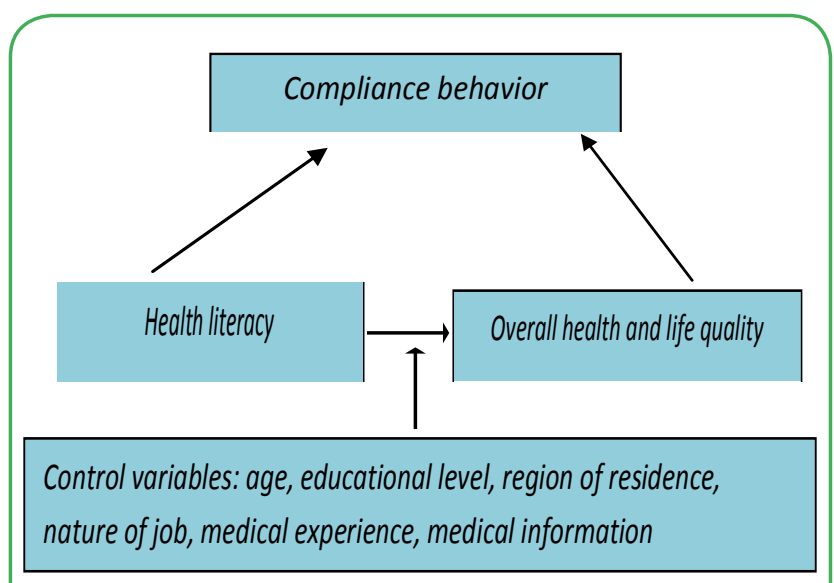

Fig. 1 The research framework 


\section{Research Samples}

The study design was explorative. A purposive sampling procedure was used. The Type II diabetic patients of internal medicine or metabolism outpatient department in seven teaching hospitals in Taiwan were collected as the study samples. Among the hospitals, three are located in metropolitan areas, and four are located in nonmetropolitan areas. Prior to the conduction of interviews, consent was obtained from the Hospital Ethics Committee, and all the subjects were requested to fill out the consent form. The research survey was conducted from November 15th, 2007 to March 31st, 2008. A total of 650 people were interviewed, and 519 copies were valid questionnaire copies.

\section{Research Tools}

The questionnaire survey method was adopted to measure the health literacy, SF-12 of health status, and personality traits. In addition to the continued use of Ware shortened health status questionnaire for SF-12[20], the rest of the questionnaire items were self-developed by the researchers.

Regarding the health literacy measurement tool, based on the definitions of health literacy and past literatures, coupled with the handbook for diabetes health prepared by the Bureau of Health Promotion, Department of Health, R.O.C. (Taiwan) as a reference for health knowledge, 25 questions covering five dimensions, foot care included, were designed to measure literacy pertaining to diabetes information-based reading, calculation, and judgment. The answers are in multiple choices (one was to be chosen out of the four choices). As this measurement tool was self-developed, after the initial scales were completed, 8 diabetes specialists, dieticians, and senior diabetes health educators conducted surface validity measurements through the 9-point Likert scale. The questions that reached more than 0.75 were retained, and the rest were eliminated. Then, 90 people (30 people were aged over 40, 30 people were university students, and 30 people were medical personnel) were invited take the pre-test and split-half reliability measurement. The measured Cronbach's $\alpha$ was 0.76 , indicating the reliability and validity were within the acceptable range.

Concerning the initial stage of the design, the scales consisted of 5 dimensions, including knowledge of the causes of diabetes (5 questions), foot care knowledge (6 questions), self-care ability (6 questions), diabetes drug use (5 questions), and calculation of figures (3 question), a total of 25 questions. In this study, in order to verify the questionnaire dimensions and achieve the purpose of conciseness, the exploratory factor analysis was adopted in the measurement. The $\mathrm{KMO}$ (Kaiser-Meyer-Olkin) of the questionnaire was 0.77 , indicating the factor analysis's suitability in the factor extraction. After the factor analysis, the Eigenvalues and factor loads $(>0.4)$ were determined to be integrated into three dimensional factors: Factor 1. Causes and knowledge of diseases; Factor 2: Daily self-care ability; and Factor 3: The ability to calculate figures. After eliminating the items with lower factor loads, only 18 questions were left in the end. The remaining items were re-tested, and although the Cronbach's $\alpha$ values were relatively lower, they remained above acceptable standards.

In terms of the measurement tools of health status-the 12-item short form health status assessment, SF-12 was adopted in the measurement. SF12was used to measure the respondents' overall health status scale. The research tool was intended to save the respondents' time during the actual implementation in order to enhance the measurement completion probability. The early SF36(MOS 36-Item Short Form Survey Instrument) was condensed into 12 questions to make it convenient for the respondents to answer the questions. The question dimension includes: physiological and psychological health. The physiological health part consists of six questions, including the physiological functions, the limitations of the body-driven roles, physical pain, and general perception of health status; the psychological health part consists of six questions, including: vitality, social function, the limitations of emotion-driven roles, and psychological health. According to the results of the respondent assessment and based on the conversion formula of Ware, two scores were obtained from the converted physiological health and psychological health. The conversion method consisted of three steps. First, the questionnaire contents underwent unified coding. Every question item was transcribed into an indicator variable: 1 represents the item was selected, 0 represents the item was not selected. Secondly, the indicator variable was multiplied by the weighted score to derive at the original score of the physiological score and psychological score. Thirdly, the physiological and psychological health scores were converted into norm-based scores based on the weighted scores obtained from researches from the United States. The results served as the scores of the respondents' physiological and psychological health scores in the follow-up analysis.

The main purpose of the control variables in the research tool was to collect the respondents' basic information, compliance behaviors, and health information acquisition channels, a total of 15 questions, including age, gender, city of residence, educational level, occupation, main sources of health information acquisition, history of diabetes, whether or not medication and injections are administered according to the doctor's instructions, the frequency of self-administered blood sugar measurement, medicine intake reminder, whether or not direct blood relatives have diabetes, whether or not traditional therapies were used to treat the disease, etc. In addition, according to WHO's definition, compliance behavior refers to the degree of consistency between an individual's behavior and the health recommendations, thereby achieving consistency between the individual's chosen behavior and the health treatment suggestions agreed by professionals. Hence, the abovementioned variables of "whether or not medication and injections are administered according to the doctor's instructions" and "the frequency of self-administered blood sugar measurement" are defined in this study as the explanatory variables of the medical compliance behaviors [21].

\section{Data Analysis Method}

The SPSS 18.0 was adopted in this study as the data analysis method to engage in descriptive statistics, reliability analysis, and correlation and regression analysis on the extracted questionnaire data. Additionally, Liseral 8.5 was adopted to analyze the three dimensions that underwent the confirmatory factor analysis. In order to explore the correlations among health literacy, compliance behavior, and health status, the hierarchical regression analysis, coupled with the structural equation modeling were adopted for model validation. In terms of the hierarchical regression analysis, the first step involved the inclusion of the control variables (Model 1), the second step involved the inclusion of the independent variables (Model 2), the third step involved the inclusion of the compliance behavior variables (Model 3 ), and the fourth step involved the inclusion of all the variables for analysis (Model 4). As the testing of the mediating varies is based on whether or not independent variables affect dependent variables through the compliance behavior, in Model 2, 3, and 4, whether there are changes in the significance of scandalized regression coefficients can be a criterion for determining whether mediating variables exist. In addition, the structural equation model was adopted in this study to measure the correlations among the independent variables, mediating effects, and dependent variables in the overall model, especially the influence of the mediating variables. As for the model explanation, the size of the actuarial parameter results played a determining role. The results formed include the direct effects, indirect (i.e. mediating) effects, and overall effects. Concerning evaluation of model fit, the absolute fit index, relative fit index, and parsimony fit index were adopted in this study to measure the appropriateness of the models.

\section{Results}

Sample Characteristics: The demographic characteristics of the 
respondents in the 519 copies of valid questionnaires are as listed in Table 1. Among them, $262(51 \%)$ are male. About half of the respondents were aged above 60 (257, accounting for $50 \%)$, with the average age of 59.1 years old. $35 \%$ of the respondents had a history of diabetes, for 1-4 years and 5-9 years (27\%) respectively, with the average length of 8.48 years ( 7.25 years). As for educational level, $122(24 \%)$ of the respondents were college or university graduates. As for the respondents' region of residence, metropolitan areas (47\%) and non-metropolitan area (49\%) each comprised half. $240(47 \%)$ of the respondents' direct blood relatives had diabetes, and only 78 respondents had a caregiver as a medicine intake reminder. There are six types of knowledge infiltration for diabetics: written information, related programs, health education information outpatient, general outpatient, maternity care teaching video tapes, and other. 0 represents having received none of the six knowledge infiltration methods above, and 1 represents having received one of the knowledge infiltration methods. $413(80 \%)$ of the people said they only received a single health information source. The people living in metropolitan areas were more able to self-absorb the health information sources, such as the Internet or books, while the people living in non-metropolitan areas mostly followed instructions of outpatient doctors. Among the respondents who required insulin, $88.2 \%$ had insulin injections on time in compliance with the doctor's instructions, $46.7 \%$ of the respondents measured their blood sugar at least once a month, and $55.1 \%$ of the respondents did not forget to take medicine on time.

\begin{tabular}{|c|c|c|}
\hline variables & & $\mathrm{N}(\%)$ \\
\hline \multirow[t]{2}{*}{ Gender } & Male & $262(51)$ \\
\hline & Female & $257(49)$ \\
\hline \multirow[t]{2}{*}{ Age } & Mean(SD) & $59.06(13.76)$ \\
\hline & Medium.25.75 & $59(51.69)$ \\
\hline \multirow{2}{*}{$\begin{array}{l}\text { If region of residence } \\
\text { is within metropolitan } \\
\text { areas }\end{array}$} & Yes & $264(51)$ \\
\hline & No & $255(49)$ \\
\hline \multirow[t]{4}{*}{ History of diabetes } & Less than 1 year & $61(11.8)$ \\
\hline & $1-4$ years & $122(23.5)$ \\
\hline & 5-10 years & $214(41.2)$ \\
\hline & $\begin{array}{l}\text { More than } 10 \\
\text { years }\end{array}$ & $122(23.5)$ \\
\hline \multirow[t]{2}{*}{ Treatment method } & Insulin & $93(18.13)$ \\
\hline & Oral medicine & $420(81.87)$ \\
\hline \multirow[t]{4}{*}{ Educational level } & Illiterate & $63(12)$ \\
\hline & $\begin{array}{l}\text { Elementary School } \\
\text { (including Literacy) }\end{array}$ & $157(30)$ \\
\hline & $\begin{array}{l}\text { Junior/senior high } \\
\text { school }\end{array}$ & $177(34)$ \\
\hline & $\begin{array}{l}\text { University/college } \\
\text { (or higher) }\end{array}$ & $122(24)$ \\
\hline
\end{tabular}

\section{The Health Literacy Survey Results}

The health literacy measurement results were presented through the grand mean. The grand mean was calculated by adding the scores of the questions answered by the 519 patients ( 1 point for each correct answer, and 0 point for each incorrect answer) and averaging the score. Then, the average score was divided by the number of questions. From the dimensions, the "daily self-care ability" had the highest score, with the grand mean and standard deviation of $0.76(0.22)$ respectively, followed by "cause of disease and knowledge", with the grand mean and standard deviation of $0.74(0.24)$ respectively. J Pub Health Issue Pract

Volume 2. 2018. 125

\section{The Health Literacy Survey Results}

The health literacy measurement results were presented through the grand mean. The grand mean was calculated by adding the scores of the questions answered by the 519 patients ( 1 point for each correct answer, and 0 point for each incorrect answer) and averaging the score. Then, the average score was divided by the number of questions. From the dimensions, the "daily self-care ability" had the highest score, with the grand mean and standard deviation of $0.76(0.22)$ respectively, followed by "cause of disease and knowledge", with the grand mean and standard deviation of $0.74(0.24)$ respectively.

Finally, the grand mean and standard deviation of "calculation of figures ability" are $0.44(0.31)$ respectively. The perfect scores of physiological health and psychological health are both 50. In this study, the mean of physiological health was 45.0 (standard deviation=6.08), and the mean of psychological health was 47.61 (standard deviation=6.43).

The between-group variance analysis shows that those with higher educational levels had better physical health scores, but lower psychological health scores; the males' psychological scores were higher than the females'; the respondents living in metropolitan areas had lower psychological scores than the respondents living in nonmetropolitan areas, as shown in Table 2.

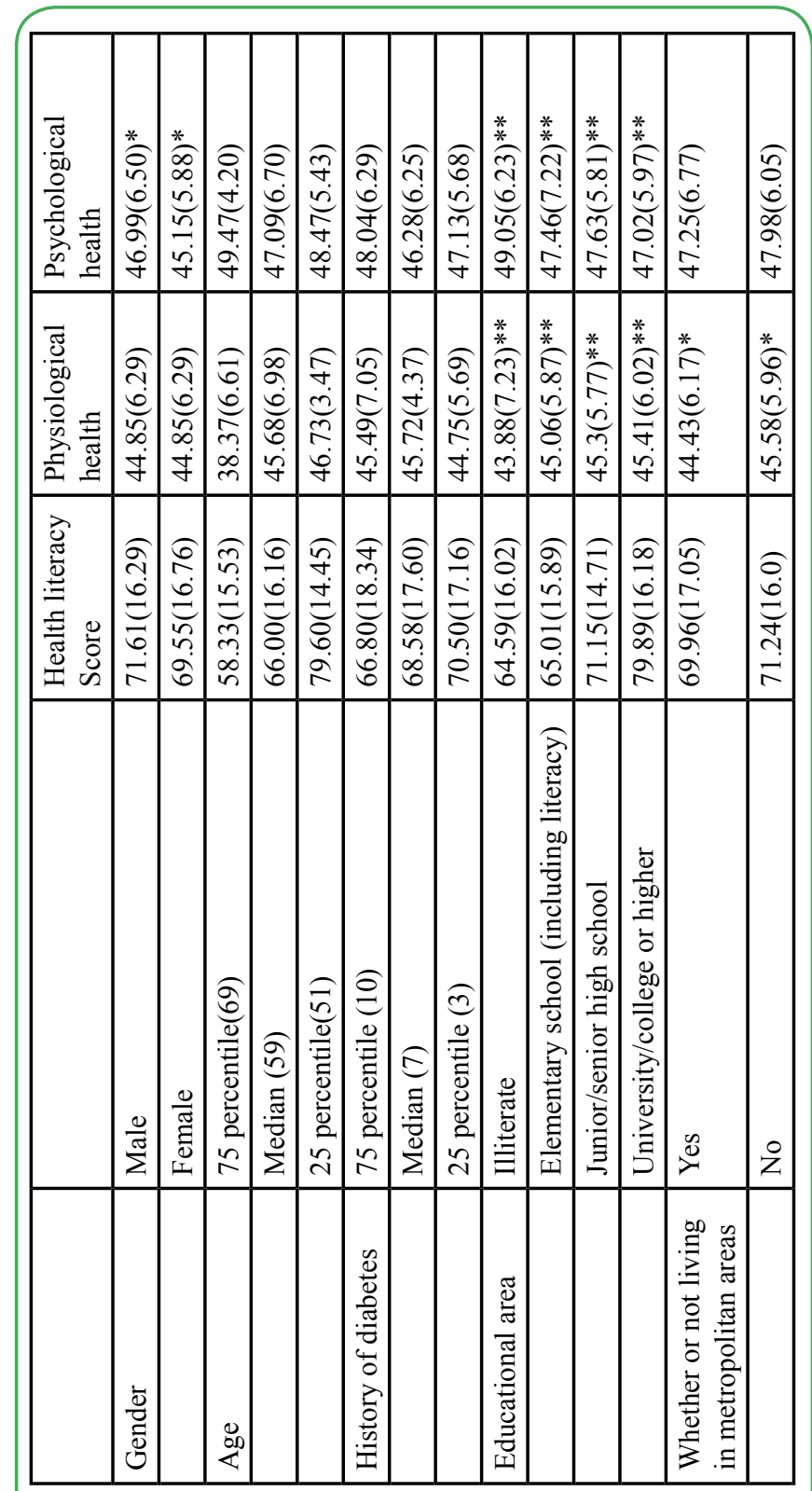

Table. 2 Cont.... 


\begin{tabular}{|l|l|l|l|l|}
\hline $\begin{array}{l}\text { The frequency of insulin injections according } \\
\text { to the doctor's instructions }\end{array}$ & No & $70.11(16.62)$ & $45.22(5.77)$ & $47.61(6.32)$ \\
\hline & Once a day & $69.59(15.88)$ & $43.18(7.96)$ & $48.25(6.09)$ \\
\hline & $2 \sim 3$ times a day & $71.27(16.82)$ & $44.14(6.96)$ & $48.11(7.31)$ \\
\hline & At least 4 times a day & $82.40(14.16)$ & $46.24(5.55)$ & $42.25(6.81)$ \\
\hline & Other & $79.83(5.49)$ & $42.58(11.40)$ & $47.68(6.84)$ \\
\hline & No & $70.06(16.62)$ & $45.12(5.90)$ & $47.71(6.31)$ \\
\hline & Once a day & $69.60(15.44)$ & $42.92(8.14)$ & $49.19(6.25)$ \\
\hline & $2 \sim 3$ times a day & $72.79(16.74)$ & $44.12(6.79)$ & $48.30(6.73)$ \\
\hline & At least 4 times a day & $82.40(14.16)$ & $46.24(5.55)$ & $42.25(6.81)$ \\
\hline & Other & $70.88(11.32)$ & $48.59(4.04)$ & $42.85(4.47)$ \\
\hline $\begin{array}{l}\text { The frequency of self-administered blood } \\
\text { sugar measurement, }\end{array}$ & No & $68.52(16.39)$ & $44.78(5.47)$ & $47.85(5.91)$ \\
\hline & & & & \\
\hline & Once a month & $71.97(16.75)$ & $45.50(6.02)$ & $47.35(5.76)$ \\
\hline & At least once a week & $73.39(15.43)$ & $45.20(7.00)$ & $48.27(6.30)$ \\
\hline & At least once a day & $74.53(17.09)$ & $44.10(7.47)$ & $46.31(7.81)$ \\
\hline & From time to time & $69.04(17.01)$ & $45.56(5.33)$ & $47.30(6.86)$ \\
\hline & Compliance & $72.82(16.39)$ & $44.14(7.09)$ & $47.54(6.76)$ \\
\hline & No compliance & $70.09(14.54)$ & $42.69(9.85)$ & $47.12(9.02)$ \\
\hline
\end{tabular}

Table 2 Analysis of between-group variances

The influential factors that possibly affected the respondents' health literacy were further analyzed. The results show that educational level was a more significant predictor. The respondents under the illiterate $(\beta=-0.24, p<0.01)$ and elementary school $(\beta=-0.36$, $\mathrm{p}<0.01$ ) categories had higher degrees of influence compared to the respondents under the junior high school (or higher) category. In addition, age was also a significant predictor $(\beta=-0.16, p<0.05)$. The higher the age, the lower the literacy score. In the regression model with physiological health as the dependent variable (as shown in Table 3), whether or not living in metropolitan areas and educational level were significant predicators. The medication compliance in the mediating variables was also a significant predictor. Additionally, in the model with psychological health as the dependent variable, the figures ability of gender and health literacy was a significant predicator. In the hierarchical regression model with compliance behavior as the medicating variable, whether or not compliance behavior was a mediating variable of health literacy and health status could not be proven. Hence, the structural equation model shall continue to be adopted to verify the relationship.

\begin{tabular}{|c|c|c|c|c|c|c|c|c|}
\hline \multirow[t]{2}{*}{ Dependent variable } & \multicolumn{4}{|c|}{ Physiological health } & \multicolumn{4}{|c|}{ Physiological health } \\
\hline & Model1 & Model2 & Model3 & Model4 & Model1 & Model2 & Model3 & Model4 \\
\hline \multicolumn{9}{|l|}{ Control variable : } \\
\hline Age & -0.02 & -0.03 & -0.02 & -0.021 & 0.11 & 0.1 & 0.11 & 0.09 \\
\hline Gender & -0.03 & -0.041 & -0.029 & -0.037 & $-0.116^{*}$ & $-0.11 *$ & $-0.121 *$ & $-0.112 *$ \\
\hline Whether living in metropolitan areas & $-0.101^{*}$ & $-0.113 * *$ & $-0.093 *$ & $-0.106^{*}$ & -0.07 & -0.06 & -0.07 & -0.06 \\
\hline \multicolumn{9}{|l|}{ Educational level } \\
\hline Illiterate & 0.1218 & 0.105 & 0.104 & 0.087 & -0.01 & -0.01 & -0.01 & -0.01 \\
\hline Elementary school & 0.268 & 0.24 & 0.259 & 0.232 & -0.09 & -0.09 & -0.1 & -0.09 \\
\hline Junior high school / senior high school & $0.287^{*}$ & 0.273 & 0.282 & 0.268 & -0.03 & -0.04 & -0.04 & -0.04 \\
\hline University/college & $0.296^{*}$ & $0.292 *$ & $0.289^{*}$ & $0.283^{*}$ & -0.02 & -0.02 & -0.03 & -0.02 \\
\hline $\begin{array}{l}\text { Whether or not direct blood relatives are } \\
\text { diabetic patients }\end{array}$ & -0.049 & -0.049 & -0.068 & -0.065 & 0.03 & 0.03 & 0.05 & 0.04 \\
\hline Disease information sources: single/diverse & 0.001 & 0.012 & 0.008 & 0.021 & 0.00 & 0.00 & 0.00 & 0.00 \\
\hline \multicolumn{9}{|l|}{ Independent variables : } \\
\hline $\begin{array}{l}\text { Factor 1-cause of disease and common } \\
\text { sense }\end{array}$ & & -0.04 & & -0.04 & & 0.01 & & 0 \\
\hline Factor 2-daily care ability & & $\begin{array}{l}-0.08 \\
0.04\end{array}$ & & $\begin{array}{l}-0.09 \\
0.06\end{array}$ & & $\begin{array}{l}0.09 \\
-0.107\end{array}$ & & $\begin{array}{l}0.09 \\
-0.109 *\end{array}$ \\
\hline
\end{tabular}

Table.3 Cont..... 


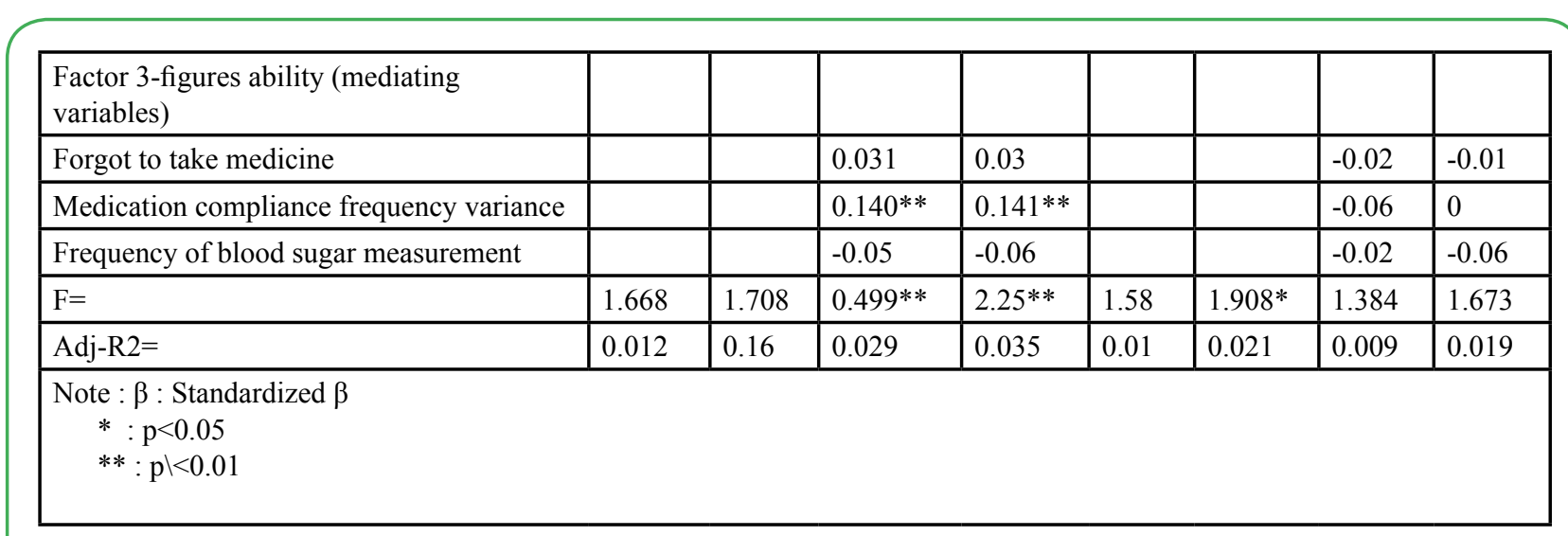

Table 3 Regression analysis with physiological health and psychological health as dependent variables

\section{Structural Equation Model}

Under the condition that the fit is acceptable in the overall model, Fig. 2 is considered the model with the best fit. As far as the model explanatory power is concerned, health literacy has a relatively lower explanatory power on doctor's order compliance, only $53 \%$. However, health literacy has a considerably high explanatory power on physiological and psychological health, $83 \%$ and $95 \%$ respectively.

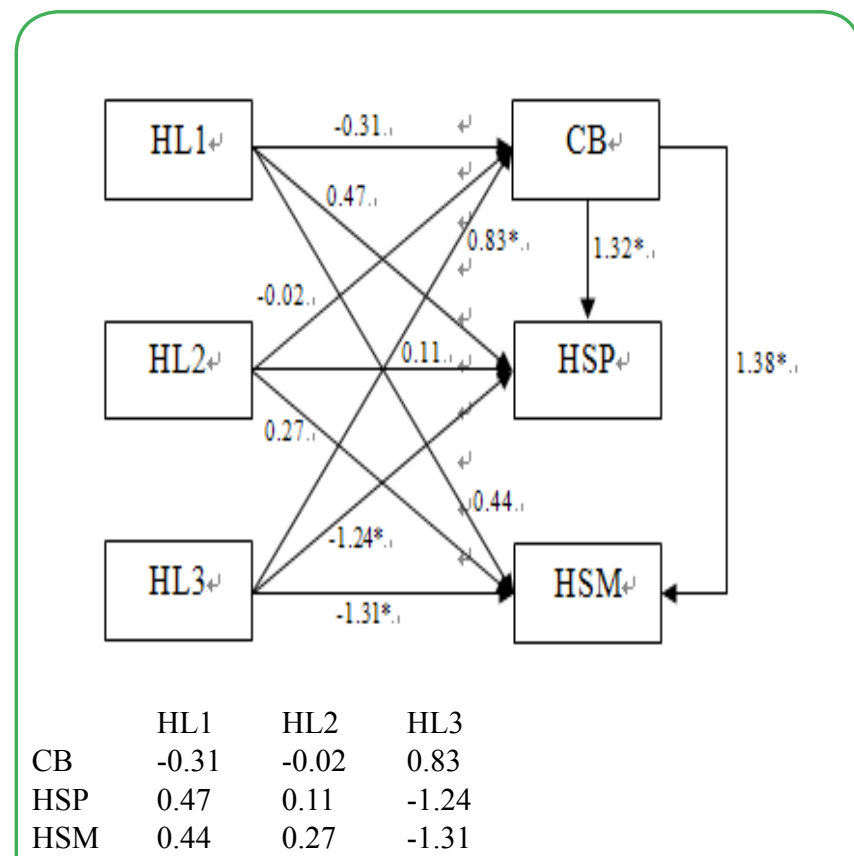

Note: HL represents the three factors of health literacy; CB represents the medical compliance behavior; HSP represents the physiological health indicators of SF12; HSM represents the psychological health indicators of SF12.

Fig. 2The research model of health literacy V.S. health status

Cohen(1988) proposed the interpretation standard for path coefficients. An absolute value of less than 0.1 indicates a weak correlation, an absolute value of 0.3 represents a moderate correlation, and an absolute value of over 0.5 represents a strong correlation. The first healthy literacy factor "Cause of disease and common sense" defined in this study showed a negative correlation with the doctor's order. In other words, the more knowledgeable the people are, the poorer their compliance with the doctor's order, thus the poorer the health status. However, this factor had a positive effect on psychological health and physiological health. The "daily selfcare ability" dimension had a positive effect on the doctor's order, indicating the higher the daily self-care ability of the people, the better their compliance with the doctor's order; it had a positive impact J Pub Health Issue Pract

Volume 2. 2018. 125 on physiological health, but its impact on psychological health produced a negative effect. Dimension 3 "calculation of figures", through the path analysis, was the most significantly effective dimension for doctor's compliance, which means it had better calculation ability and better compliance with doctor's order. However, it had a negative impact on the psychological and physiological aspect, while the people showing better compliance with doctor's order, as far as the physiological health and psychological health data are concerned, showed a positive correlation This finding indicates that doctor's order compliance is indeed the crucial factor affecting the people's health. Additionally, the compliance behavior is the mediating variable of knowledge and health status, especially in the two items: "cause of disease and knowledge" and "calculation of figures", which had direct and indirect correlations. That is, the mediating relationship of compliance behavior in health literacy and health status was supported.

\section{Discussion and Conclusion}

The three dimensions of health literacy defined in this study include: "cause of disease and knowledge", "daily self-care ability", and "calculation of figures ability." Among them, Dimension 1 "cause of disease and knowledge" and doctor's order compliance showed a negative correlation. In other words, the more knowledgeable the people were, the poorer the compliance with doctor's order, likely because of more access to information channels and their higher self-judgment ability; contrarily, it resulted in poorer compliance to doctor's order. However, this factor produced a positive impact on the health status, although only to a small extent and not reaching a statistically significant impact, it was somewhat consistent with the descriptions in the literatures. Therefore, health knowledge is to a certain extent helpful in improving the health condition.

Dimension 2 The "daily self-care ability" dimension showed a less impact on the daily self-care ability and doctor's order compliance, but it had a positive impact on physiological health and psychological health, indicating if people have the proper daily self-care ability, it will help improve the physical health and physiological health.

Dimension 3 The "figures problem" in the path analysis was the dimension with the most significant result on doctor's order compliance, which means a better ability to calculating figures gives rise to better doctor's order compliance. However, it had a negative correlation with physiological health and psychological health. In addition, according to the fit model in this study, doctor's order compliance was the most significant factor affecting health. Hence, in order to enhance doctor's order compliance through health literacy enhancement, the daily self-care ability and calculation of figures stability are needed to achieve a positive impact. Further, the daily care ability and figures ability possess both direct and indirect effects that both enhanced the health status through the compliance behavior. Therefore, it is deemed in this study that to enhance people's health status through the health literacy, the first and foremost 
thing is to upgrade people's daily self-care abilities, which is a finding that coincides with the conclusions of past researches [22].

Based on the research conclusions, as far as the diabetic patients are concerned, the level of the overall health literacy has a direct impact on the overall psychological health status, but the overall physiological health did not reach significant differences. However, by adding the intervening variables of doctor's order compliance into the model, the model with physiological health as the dependent variable produced significant differences. It can therefore be understood from the above that health literacy had a certain cause-effect relationship with the people's overall physiological or psychological health, while the intervening variable of doctor's order compliance even had a crucial impact.

Secondly, people's health literacy is entirely dependent on whether or not there is adequate health knowledge, so it is very important for them to obtain appropriate health knowledge. The related research results in literatures in recent years also derived at similar findings $[23,24]$. Therefore, through investigations on medical institutions, appropriate health information dissemination channels should e selected depending on the locations of the hospitals, so as to assist the general public in enhancing health literacy. For example, medical institutions in metropolitan areas should establish diverse health information related channels, especially through the Internet multimedia, which medical institutions in non-metropolitan areas should strengthen their medical personnel's communication skills and talent in achieving propaganda effectiveness.

Finally, it was found after examining the respondents' answers for relevant questions one by one that compared to the general text reading ability, their comprehension of the reverse questions, their ability to identify word-of-mouth wrong messages, and calculation ability were relatively weaker, and this finding shall serve as a reference for improving people's health literacy in the future. According to the fit model in this study, it was found that the health literacy dimensions defined in this study produced a direct impact on the overall health status, while disease knowledge and daily self-care ability produced a positive correlation. However, as doctor's order compliance was the major significant factor affecting health, in order to enhance doctor's order compliance through health literacy, the daily self-care ability and calculation of figures ability are needed to achieve a positive impact. Hence, regardless of a direct impact or indirect impact, the daily self-care ability can produces an impact. In this study, it is therefore deemed that in order to enhance people's health status by means of enhancing health literacy, the first and foremost ability to improve is the daily self-care ability of the general public. According to past literatures on health literacy, it is proven that those with poor health literacy levels tend to be relatively deficient of health knowledge [25-27]. As a result, from the descriptions of this study, it can be understood that health knowledge terms that are more difficult to understand and methods to control chorionic diseases of patients indeed affect people's health literacy level, thus resulting in poorer knowledge measurement results. This conclusion coincides with past researches that the health literacy level and health knowledge has a positive correlation. Because people with poorer knowledge means they do not know how to take proper actions and find information channels to obtain correct health knowledge, healthcare providers should take into account the provision of health knowledge and self-care methods to educate the general public, so as to help patients with poorer health literacy understand how to take care of their disease and improve their health literacy, thereby improving their health status.

In terms of research limitations, the health literacy in this study is a self-developed research tool. According to the framework of Nutbeam's level of health literacy [6], the concept of the measurement tool design was established based on related health knowledge, so as to explore whether or not the general public that underwent the test converted related knowledge into actual behaviors to improve their level of health literacy. Although the experts conducted surface validity on the research tool and screened the questions and regrouped the questionnaire dimensions through factor analysis, perhaps because the subjects' were relatively older, the self-care of diabetes and related knowledge test questions were relatively more difficult, thus the low correct answer rates. Hence, follow-up researches may, targeting the correlation between health knowledge and health literacy, perform more tests. At the same time, it is suggested that the questionnaire distinctiveness be further validated and the design content be adjusted in follow-up researches.

\section{Acknowledgement}

This research was supported in part by the Ministry of Science and Technology of the Republic of China (grant number MOST 1072410-H-242-001)

\section{Reference}

1. Kirsch IJA, Jenkins L, Kolstad A (1993) Adult Literacy in America: A First Look at the Results of the National Adult Literacy Survey: U.S. Government Printing Office, Superintendent of Documents, Washington, DC 20402 (Stock No. 065-000-00588-3).

2. America-medical-association (2006) Health Literacy.

3. Davis TC, Williams MV, Marin E, Parker RM, Glass J et al. (2002) Health Literacy and Cancer Communication. CA Cancer $\mathrm{J}$ Clin 52:134-149.

4. World-Health-Organization (1998) editor. Health promotion glossary: World Health Organization.

5. Pender NJ (1996) Health promotion in nursing practice. East Norwalk: Appleton \& Lange.

6. Nutbeam D (2000) Health literacy as a public health goal: A challenge for contemporary health education and communication strategies into the 21 st century. Health Promotion International 15: 259-267.

7. Williams MV, Baker DW, Parker RM, Nurss JR (1998) Relationship of functional health literacy to patients' knowledge of their chronic disease. A study of patients with hypertension and diabetes. Arch Internal Med 158: 166-172.

8. Gazmararian JA, Baker DW, Williams MV, Parker RM, Scott TL et al. (1999) Health literacy among medicare enrollees in a managed care organization. JAMA : J Am Med Assoc 281: 545-551.

9. Gazmararian JA, Williams MV, Peel J, Baker DW (2003) Health literacy and knowledge of chronic disease. Patient Education and Counseling 51: 267-275.

10. Baker DW, Parker RM, Williams MV, Clark WS, Nurss J et al. (1997) The relationship of patient reading ability to selfreported health and use of health services. Am J Pub Health 87: 1027-1030.

11. Von Wagner C, Steptoe A, Wolf MS, Wardle J (2009) Health literacy and health actions: A review and a framework from health psychology. Health education \& behavior : The Official Publication of the Society for Public Health Education 36: 860877.

12. Chen A, Mond JM, Kumar R (2010) Eating disorders mental health literacy in Singapore: Beliefs of young adult women concerning treatment and outcome of bulimia nervosa. Early Intervention in Psychiatry 4: 39-46.

13. Morris NS, MacLean CD, Littenberg B (2006) Literacy and health outcomes: A cross-sectional study in 1002 adults with diabetes. BMC Family Practice 7: 49. 
14. Powell CK, Hill EG, Clancy DE (2007) The relationship between health literacy and diabetes knowledge and readiness to take health actions. The Diabetes Educator 33: 144-151.

15. Kalichman SC, Ramachandran B, Catz S (1999) Adherence to combination antiretroviral therapies in HIV patients of low health literacy. J Gen Intern Med 14: 267-273.

16. Scott TL, Gazmararian JA, Williams MV, Baker DW (2006) Health literacy and preventive health care use among medicare enrollees in a managed care organization. Medical Care. 2002; 40: 395-404.

17. Wilkinson GS. WRAT-3: (1993) Wide range achievement test administration manual Wide Range.

18. Davis TC, Long SW, Jackson RH, Mayeaux EJ, George RB, et al. (1993) Rapid estimate of adult literacy in medicine: A Shortened Screening Instrument. Family Medicine. 1993; 25: 391-395.

19. Parker R, Baker D, Williams M, Nurss J (1995) The test of functional health literacy in adults. J Gen Internal Med. 10: 537-541.

20. JE W, M K, SD K. SF-12: (1995) How to score the SF-12 physical and mental health summary scales. Boston, MA:: The Health Institute, New England Medical Center.

21. World-Health-Organization (1998) Health promotion glossary: Geneva: World Health Organization.

22. Curtin RB, Sitter DC, Schatell D, Chewning BA (2004) Selfmanagement, knowledge, and functioning and well-being of patients on hemodialysis. Nephrology Nursing Journal : J Am Nephrol Nurses' Assoc 31: 378-386.

23. Carolan M (2007) Health literacy and the information needs and dilemmas of first-time mothers over 35 years. J Clin Nurs 16: 1162-1172.

24. Flaskerud JH (2007) Cultural competence column: What else is Necessary? Issues in Mental Health Nursing 28: 219-222.

25. Spandorfer JM, Karras DJ, Hughes LA, Caputo C (1995) Comprehension of Discharge Instructions by Patients in an Urban Emergency Department. Annals of Emergency Medicine 25: 71-74.

26. TenHave Tr Fau - Van Horn B, Van Horn B Fau - Kumanyika S, Kumanyika S Fau - Askov E, Askov E Fau - Matthews Y, Matthews Y Fau - Adams-Campbell LL, Adams-Campbell LL. Literacy Assessment in a Cardiovascular Nutrition Education Setting.

27. Williams MV, Baker DW, Honig EG, Lee TM, Nowlan A et al. (1998) Inadequate literacy is a barrier to asthma knowledge and self-care. Chest 114: 1008-1015. 